Journal Club

Editor's Note: These short, critical reviews of recent papers in the Journal, written exclusively by graduate students or postdoctoral fellows, are intended to summarize the important findings of the paper and provide additional insight and commentary. For more information on the format and purpose of the Journal Club, please see http://www.jneurosci.org/misc/ifa_features.shtml.

\title{
Sex, Impulsivity, and Anxiety: Interplay between Ventral Striatum and Amygdala Reactivity in Sexual Behaviors
}

\author{
Mateusz Gola, ${ }^{1,2}$ Makoto Miyakoshi, ${ }^{1}$ and Guillaume Sescousse ${ }^{3}$ \\ ${ }^{1}$ Swartz Center for Computational Neuroscience, Institute for Neural Computations, University of California San Diego, La Jolla, California 92093-0559, \\ ${ }^{2}$ Institute of Psychology, Polish Academy of Science, 00-378 Warsaw, Poland, and ${ }^{3}$ Donders Institute for Brain, Cognition, and Behaviour, Radboud \\ University, 6525 EZ Nijmegen, The Netherlands \\ Review of Victor et al.
}

Comorbidity of mood/anxiety disorders and addictive behaviors is widely reported in the clinical literature. Many psychological models of addictive and risk behaviors assume an appetitive component (related to impulsivity) and/or a mood regulation component (related to anxiety; Verheul et al., 1999; Raymond et al., 2003). Surprisingly, most human neuroimaging studies have focused on the first aspect, primarily examining dysfunctions of the brain reward circuitry, mainly the ventral striatum (VStr). Fewer studies have examined the role of the amygdala, which may contribute to the anxiety component of human addictive behaviors. For instance, the latter studies have shown that reduced threat-related amygdala activity may be associated with diminished reactions to hazards and vulnerability to substance abuse (Glahn et al., 2007; Hariri et al., 2009).

Two recent studies have examined the interaction of reward and threat processing in relation to potentially risky behaviors. Victor et al. (2015) showed a link between VStr versus amygdala functioning and sexual behavior, while Nikolova et

\footnotetext{
Received Aug. 31, 2015; revised 0ct. 11, 2015; accepted 0ct. 23, 2015 All authors are postdoctoral researchers.

The authors declare no competing financial interests.

Correspondence should be addressed to Mateusz Gola, University of

California, San Diego, SCCN, 9500 Gilman Drive \# 0559, La Jolla, CA 92093 0559. E-mail:mgola@ucsd.edu.

DOI:10.1523/JNEUROSCI.3273-15.2015

Copyright $\odot 2015$ the authors $\quad 0270-6474 / 15 / 3515227-03 \$ 15.00 / 0$
}

al. (2015) examined the interplay of these brain areas in alcohol use disorder.

Victor et al. (2015) examined VStrreward reactivity and amygdala-threat reactivity in a group of 70 heterosexual young adults (18-22 years old) using two experimental tasks. A card-guessing game was used to investigate VStr reactivity: participants received positive or negative feedback and VStr-reward reactivity was measured with fMRI as the blood oxygenation leveldependent (BOLD) signal difference between positive and negative feedback. A facial discrimination task was used to measure amygdala reactivity: participants were presented with three photographs of faces (with neutral, angry, fearful, or surprised expressions) and had to match one of the two faces presented at the bottom of the screen with the target face displayed at the top. During control blocks, participants matched simple geometric shapes. Amygdala-threat reactivity was measured as the BOLD difference between face and shape trials.

The authors found that in men, relatively high VStr-reward reactivity and low amygdala-threat reactivity was associated with a greater number of new vaginal sex partners (VSPs) in a period of 3-20 months following the study [Victor et al. (2015), their Fig. 2]. In contrast, a greater number of new VSPs for women was associated with relatively high VStr-reward reactivity and high amygdala-threat reactivity [Victor et al. (2015), their Fig. 1].
The authors interpret their findings in the broader and societally relevant context of sexual risk behaviors. They implicitly equate the number of sexual partners to sexual risk behavior, and suggest that the observed patterns of brain activity in the VStr and amygdala are predictive of such behaviors, e.g., the contraction of sexually transmitted infections (STIs). However, we think this might be a bold leap. Sexual risk behaviors are usually defined by the increased probability of two distinct outcomes: (1) occurrence of unwanted pregnancy and (2) infection with an STI (Whaley, 1999). Unwanted pregnancy is related to frequency of penile-vaginal intercourse without contraception. The risk of contracting STIs is determined by several factors, among which the most important is consistent condom use (Wen et al., 1999; Baldwin et al., 2004; Hsu et al., 2015). For example, many studies on genital human papillomavirus (HPV) infection, one of the most common STIs, show that it is most strongly associated with poor condom use (Kjaer et al., 2005) and frequency of intercourse (Baldwin et al., 2004), but not with the number of VSPs (for review, see Partridge and Koutsky, 2006). Furthermore, other studies demonstrated that the predominant risk factor for HPV infection in young women is related not only to their own sexual behaviors but also to those of their male partners (Burk et al., 1996). In light of such evidence, we think that the measure of new VSPs as used by Victor et al. (2015) is insufficient to make a 
link between brain activity patterns and sexual risk behaviors. To make such a claim, further studies controlling the consistency of condom use, frequency of intercourse, and knowledge about the partners' sexual activity will be required.

In addition, we think that the genderspecific effects reported in the study by Victor et al. (2015) should be treated with caution. Based on the data shared with us by the authors, only 6 of 48 females and 3 of 24 males reported two or more new VSPs in the period following the fMRI experiment. To ensure that opposite amygdala-threat reactivity (high in females vs low in males) is not an effect of individual differences between these 6 female and 3 male individuals, these results should be replicated with larger samples of highly sexually active adults.

Despite these concerns, the results of Victor et al. (2015) are consistent with other recent findings from the same research group. Specifically, Nikolova et al. (2015) showed that in the context of stress, problematic alcohol drinking was highest in individuals expressing one of two opposite neural phenotypes: (1) high VStr-reward reactivity and low amygdala-threat reactivity or (2) low VStr-reward reactivity and high amygdala-threat reactivity. This effect was the same for men and women. It is noteworthy that the first group showed a pattern of brain activity similar to that observed for males in the study by Victor et al. (2015). In addition, Nikolova et al. (2015) performed mediation analyses providing evidence that the relationship between stress and problem drinking was specifically mediated by impulsivity (measured by delaydiscounting behavior) in the first group, and by anxious/depressive symptoms (measured with self-report questionnaire) in the second group. These results may reflect some interplay between impulsivity and inhibition of anxiety. Subjects with low anxiety levels may impulsively engage in problematic behavior. When threat-induced amygdala activation is too high, the same problematic behavior may be engaged in to reduce anxiety. In contrast to the study by Nikolova et al. (2015), Victor et al. (2015) did not include measures of impulsivity or anxiety. It would be interesting to include such measures in future studies, to assess their role as mediators in the relationship between VStr/amygdala reactivity and sexual behaviors.

It is worth noting that VStr-reward reactivity was measured in the context of monetary rewards in both the studies by Nikolova et al. (2015) and Victor et al. (2015). Interestingly, this reactivity to monetary rewards was related to alcohol abuse (Nikolova et al., 2015) and sexual behavior (Victor et al., 2015). This suggests that VStr reactivity in both studies may be associated not with domainspecific (i.e., selectively for alcohol or sex), but rather with general impulsivity, as previously suggested by Forbes et al. (2009) using the same procedure. Many behavioral studies have shown that sexual risk behaviors are indeed related to general impulsivity (Charnigo et al., 2013; Dir et al., 2014) regardless of gender or sexual orientation (King et al., 2012; Hutton et al., 2013; Heidinger et al., 2015). However, more detailed observations of clinical populations indicate that some individuals exhibit a bias for sexual behaviors over other reward-seeking behaviors (i.e., gambling; Kor et al., 2014). Valuable insight for understanding such symptoms comes from studies showing that the relative reactivity of the VStr toward different types of cues scales with the relative motivation to approach those cues. For example, Sescousse et al. (2013) have shown that the severity of pathological gambling symptoms is related to the relative VStr reactivity toward monetary compared with erotic cues. Similarly, a recent study by Demos et al. (2012) showed that the VStr BOLD response to erotic pictures (compared with baseline) was predictive of sexual desire at 6-month follow up, whereas the VStr response to other stimuli (food, people, alcohol, nature) was not predictive of this desire. Similar specific relationships between VStr responses to food images and body-mass index change have been reported in the study by Demos et al. (2012). We think that the examination of such cue-specific effects will be important in future studies on sexual risk behaviors and out-of-control sexual behaviors (OCSBs), which include excessive consumption of pornography and paid sexual services. There is ongoing discussion among therapists and researchers about how to conceptualize OCSBs (Levine, 2010; but see Kafka, 2010). Two of the most discussed frameworks are as follows: addictive behavior related to sexual-specific VStr-reactivity and obsessive-compulsive disorder related to anxiety regulation (Kor et al., 2014; Voon et al., 2014; vs Ley et al., 2014; vs Prause et al., 2015). Although the study by Victor et al. (2015) did not assess these cue-specific effects, the authors convincingly emphasized the importance of the interaction between VStr-reward reactivity and amygdala-threat reactivity for better understanding sexual risk behaviors. This interaction should provide a valuable framework for studying conditions like OCSB. Investigating VStr/amygdala interactions should help disentangle impulsive and affective neural mechanisms underlying OCSBs and examine homogeneity of these symptoms.

To conclude, the study by Victor et al. (2015) indicates that among young adults, high VStr-reward reactivity may be related to a greater number of VSPs when accompanied by low amygdala-threat reactivity in men and high amygdala-threat reactivity in women. Despite the fact that some of the links that connect brain functions with sexual risk behaviors are missing, the importance of the present study is nevertheless evident. The observed interaction between VStr-reward reactivity and amygdala-threat reactivity in the context of sexual behaviors provides a promising framework for future research on addictive and risk behaviors, including OCSBs. For future studies, researchers would be well advised to control and report consistency of condom use and frequency of intercourse. It will also be of interest to clarify how the reported brain activation patterns are related to sexual behavior specifically or to general impulsivity.

\section{References}

Baldwin SB, Wallace DR, Papenfuss MR, Abrahamsen M, Vaught LC, Giuliano AR (2004) Condom use and other factors affecting penile human papillomavirus detection in men attending a sexually transmitted disease clinic. Sex Transm Dis 31:601-607. Medline

Burk RD, Ho GY, Beardsley L, Lempa M, Peters M, Bierman R (1996) Sexual behavior and partner characteristics are the predominant risk factors for genital human papillomavirus infection in young women. J Infect Dis 174: 679-689. CrossRef Medline

Charnigo R, Noar SM, Garnett C, Crosby R, Palmgreen P, Zimmerman RS (2013) Sensation seeking and impulsivity: combined associations with risky sexual behavior in a large sample of young adults. J Sex Res 50:480-488. CrossRef Medline

Demos KE, Heatherton TF, Kelley WM (2012) Individual differences in nucleus accumbens activity to food and sexual images predict weight gain and sexual behavior. J Neurosci 32:5549-5552. CrossRef Medline

Dir AL, Coskunpinar A, Cyders MA (2014) A meta-analytic review of the relationship between adolescent risky sexual behavior and impulsivity across gender, age, and race. Clin Psychol Rev 34:551-562. CrossRef Medline

Forbes EE, Brown SM, Kimak M, Ferrell RE, Manuck SB, Hariri AR (2009) Genetic variation in components of dopamine neurotransmission impacts ventral striatal reactivity associated with impulsivity. Mol Psychiatry 14:60-70. CrossRef Medline

Glahn DC, Lovallo WR, Fox PT (2007) Reduced amygdala activation in young adults at high 
risk of alcoholism: studies from the Oklahoma Family Health Patterns Project. Biol Psychiatry 61:1306-1309. CrossRef Medline

Hariri AR, Gorka A, Hyde LW, Kimak M, Halder I, Ducci F, Ferrell RE, Goldman D, Manuck SB (2009) Divergent effects of genetic variation in endocannabinoid signaling on human threat- and reward-related brain function. Biol Psychiatry 66:9-16. CrossRef Medline

Heidinger B, Gorgens K, Morgenstern J (2015) The effects of sexual sensation seeking and alcohol use on risky sexual behavior among men who have sex with men. AIDS Behav 19: 431-439. CrossRef Medline

Hsu HT, Wenzel S, Rice E, Gilreath TD, Kurzban S, Unger J (2015) Understanding consistent condom use among homeless men who have sex with women and engage in multiple sexual partnerships: a path analysis. AIDS Behav 19: 1676-1688. CrossRef Medline

Hutton HE, McCaul ME, Chander G, Jenckes MW, Nollen C, Sharp VL, Erbelding EJ (2013) Alcohol use, anal sex, and other risky sexual behaviors among HIV-infected women and men. AIDS Behav 17:1694-1704. CrossRef Medline

Kafka MP (2010) "What is sexual addiction?" A response to Stephen Levine. J Sex Marital Ther 36:276-281. CrossRef Medline

King KM, Nguyen HV, Kosterman R, Bailey JA, Hawkins JD (2012) Co-occurrence of sexual risk behaviors and substance use across emerging adulthood: evidence for state- and trait-level associations. Addiction 107:12881296. CrossRef Medline
Kjaer SK, Munk C, Winther JF, Jørgensen HO, Meijer CJ, van den Brule AJ (2005) Acquisition and persistence of human papillomavirus infection in younger men: a prospective follow-up study among Danish soldiers. Cancer Epidemiol Biomarkers Prev 14:15281533. CrossRef Medline

Kor A, Zilcha-Mano S, Fogel YA, Mikulincer M, Reid RC, Potenza MN (2014) Psychometric development of the Problematic Pornography Use Scale. Addict Behav 39:861-868. CrossRef Medline

Levine SB (2010) What is sexual addiction? J Sex Marital Ther 36:261-275. CrossRef Medline

Ley D, Prause N, Finn P (2014) The emperor has no clothes: a review of the "pornography addiction" model. Curr Sex Health Rep 6:94105. CrossRef

Nikolova YS, Knodt AR, Radtke SR, Hariri AR (2015) Divergent responses of the amygdala and ventral striatum predict stress-related problem drinking in young adults: possible differential markers of affective and impulsive pathways of risk for alcohol use disorder. Mol Psychiatry. Advance online publication. Retrieved July 14, 2015. CrossRef

Partridge JM, Koutsky LA (2006) Genital human papillomavirus infection in men. Lancet Infect Dis 6:21-31. CrossRef Medline

Prause N, Steele VR, Staley C, Sabatinelli D, Hajcak G (2015) Modulation of late positive potentials by sexual images in problem users and controls inconsistent with "porn addiction." Biol Psychol 109:192-199. CrossRef Medline
Raymond NC, Coleman E, Miner MH (2003) Psychiatric comorbidity and compulsive/impulsive traits in compulsive sexual behavior. Compr Psychiatry 44:370-380. CrossRef Medline

Sescousse G, Barbalat G, Domenech P, Dreher JC (2013) Imbalance in the sensitivity to different types of rewards in pathological gambling. Brain 136:2527-2538. CrossRef Medline

Verheul R, van den Brink W, Geerlings P (1999) A three-pathway psychobiological model of craving for alcohol. Alcohol Alcohol 34:197222. CrossRef Medline

Victor EC, Sansosti AA, Bowman HC, Hariri AR (2015) Differential patterns of amygdala and ventral striatum activation predict genderspecific changes in sexual risk behavior. J Neurosci 35:8896-8900. CrossRef Medline

Voon V, Mole TB, Banca P, Porter L, Morris L, Mitchell S, Lapa TR, Karr J, Harrison NA, Potenza MN, Irvine M (2014) Neural correlates of sexual cue reactivity in individuals with and without compulsive sexual behaviours. PLoS One 9:e102419. CrossRef Medline

Wen LM, Estcourt CS, Simpson JM, Mindel A (1999) Risk factors for the acquisition of genital warts: are condoms protective? Sex Transm Infect 75:312-316. CrossRef Medline

Whaley AL (1999) Preventing the high-risk sexual behavior of adolescents: focus on HIV/ AIDS transmission, unintended pregnancy, or both? J Adolesc Health 24:376-382. CrossRef Medline 